Research Paper

\title{
Comparison of Retroflexed and Forward Views for Colorectal Endoscopic Submucosal Dissection
}

\author{
Shintaro Fujihara ${ }^{\bowtie}$, Hideki Kobara, Hirohito Mori, Yasuhiro Goda, Taiga Chiyo, Tae Matsunaga, Noriko \\ Nishiyama, Maki Ayaki, Tatsuo Yachida, and Tsutomu Masaki \\ Departments of Gastroenterology and Neurology, Faculty of Medicine, Kagawa University, Japan
}

$\triangle$ Corresponding author: Shintaro Fujihara, MD, Department of Gastroenterology and Neurology, Faculty of Medicine, Kagawa University, 1750-1 Ikenobe, Miki-cho, Kita-gun, Kagawa 761-0793, Japan. Tel: +81-87-891-2156. Fax: +81-87-891-2158. E-mail: joshin@med.kagawa-u.ac.jp

C 2015 Ivyspring International Publisher. Reproduction is permitted for personal, noncommercial use, provided that the article is in whole, unmodified, and properly cited. See http://ivyspring.com/terms for terms and conditions.

Received: 2015.02.18; Accepted: 2015.05.18; Published: 2015.05.26

\begin{abstract}
Background: The use of a retroflexed view exposes the entire tumor surface, which is obscured in the forward view, and contributes to complete tumor resection when combined with forward views. However, the efficacy and safety of using the retroflexed view for colorectal endoscopic submucosal dissection (ESD) are poorly understood.

Methods: In this study, we assessed the efficacy and safety of the retroflexed view in colorectal ESD. From April 2009 to December 2013, 130 colorectal tumors were examined in 128 patients treated with ESD. A total of 119 patients with a mean tumor size of $27.2 \mathrm{~mm}$ were enrolled in the study, and these patients were assigned to undergo colorectal ESD with or without a retroflexed view.

Results: The use of retroflexion was successful in $84.2 \%$ of patients. There were no perforations in the study and no complications related to the use of retroflexed views. The mean procedure time was $103.6 \pm 55.8 \mathrm{~min}$ in the retroflexed group, as compared with $108.0 \pm 66.5 \mathrm{~min}$ in the forward view group. The mean procedure time for resecting tumors $>40 \mathrm{~mm}$ was significantly shorter in the retroflexed group relative to the forward group. Additionally, the mean dissection speed per unit area was significantly faster in the retroflexed group, as compared with the forward group.

Conclusions: Retroflexed views can be used to remove lesions $>40 \mathrm{~mm}$ and shorten procedure times. Retroflexion may also contribute to an improved en bloc resection rate.
\end{abstract}

Key words: endoscopic submucosal dissection; colorectal cancer; retroflexion; laterally spreading tumor; procedure time

\section{Background}

Endoscopic submucosal dissection (ESD) is widely used to treat gastrointestinal cancer. This approach provides a high rate of en bloc resection for large colorectal tumors and is reportedly effective in 88.0-94.5\% of cases (1-3). However, ESD has not yet been recognized as a conventional therapeutic procedure for early colorectal carcinoma, and this procedure has not been standardized because of its associated technical challenges (4). Moreover, because the colonic wall is thinner than the gastric wall and there are many folds in the colon and rectum, some lesions are difficult to access during colorectal ESD because of their location on the proximal sides of folds or flexures.

The retroflexion technique exposes the entire tumor surface, which is obscured in the forward view (5-6), and contributes to complete tumor resection when combined with forward views (7). Previously, retroflexion techniques have been used to improve the detection of neoplasia in the distal rectum (8) and 
proximal colon (9), as well as lesions that are difficult to access with the forward view (5). Although retroflexion techniques have become easier and safer owing to recent advances in equipment (10-11), the efficacy and safety of retroflexion techniques for colorectal ESD remain unclear. Therefore, in this study, we examined whether the retroflexion method affected the safety and efficacy of colorectal ESD.

\section{Methods}

Between April 2009 and April 2013, 130 colorectal tumors in 128 patients were resected by ESD at our institute (Figure 1). The indications for colorectal ESD at our institution are as follows: (i) colorectal carcinoma $>20 \mathrm{~mm}$ in size, which is considered curable according to magnification endoscopy or endoscopic ultrasound findings and is difficult to resect en bloc; (ii) colorectal adenoma with a non-lifting sign after endoscopic injection; and (iii) residual or recurrent colorectal adenoma $>10 \mathrm{~mm}$ in size, which is difficult to resect by conventional endoscopic mucosal resection (EMR). We examined all lesions using magnifying endoscopy prior to endoscopic therapy and determined the indications for ESD or EMR in accordance with current guidelines. The following exclusion criteria were applied: 1) lesions that could result in en bloc resection by EMR; 2) lesions located in the anal canal or in the appendix; 3) tumor size $>70 \mathrm{~mm}$; 4 ) severe organ failure; 5) current anticoagulant therapy; and 6) an inability to obtain written informed consent. The remaining nine patients were excluded from the present study for the following reasons: ESD was at- tempted but abandoned $(\mathrm{n}=5)$; tumor size was $>100$ $\mathrm{mm}(\mathrm{n}=5)$; and the tumor was a carcinoid $(\mathrm{n}=3)$.

In this retrospective study, 108 lesions were resected using ESD and 11 lesions were resected by snaring after circumferential incision and limited submucosal dissection (hybrid ESD). All ESD procedures were performed by three experienced endoscopists (H.M., H.K. and M.K.; H.M. has successfully performed $>350$ gastric and 200 colorectal ESD procedures, H.K. has performed $>100$ gastric and 50 colorectal ESD procedures, and M.K. has performed $>100$ gastric and 50 colorectal ESD procedures). This study was approved by the ethics committee of Kagawa University Medical and Dental Hospital, and written informed consent was obtained from all patients.

\section{Participants}

The invasion depth was limited to mucosal or submucosal (SM)1, as estimated endoscopically and by chromoendoscopic magnification in most cases (12). Based on extensive clinicopathological analyses (13-15), we defined the indications for ESD (16) as nongranular laterally spreading tumors (LST-NG) $>20$ $\mathrm{mm}$ and granular LSTs (LST-G) $>30 \mathrm{~mm}$. Both tumor types have high SM invasion rates and are difficult to treat even by piecemeal EMR $(13,15)$. Large villous tumors and intramucosal lesions, recurrent lesions, and residual mucosal lesions that showed evidence of non-lifting (17-18) after EMR were also potential candidates for ESD. The final treatment decision was made by each individual endoscopist.

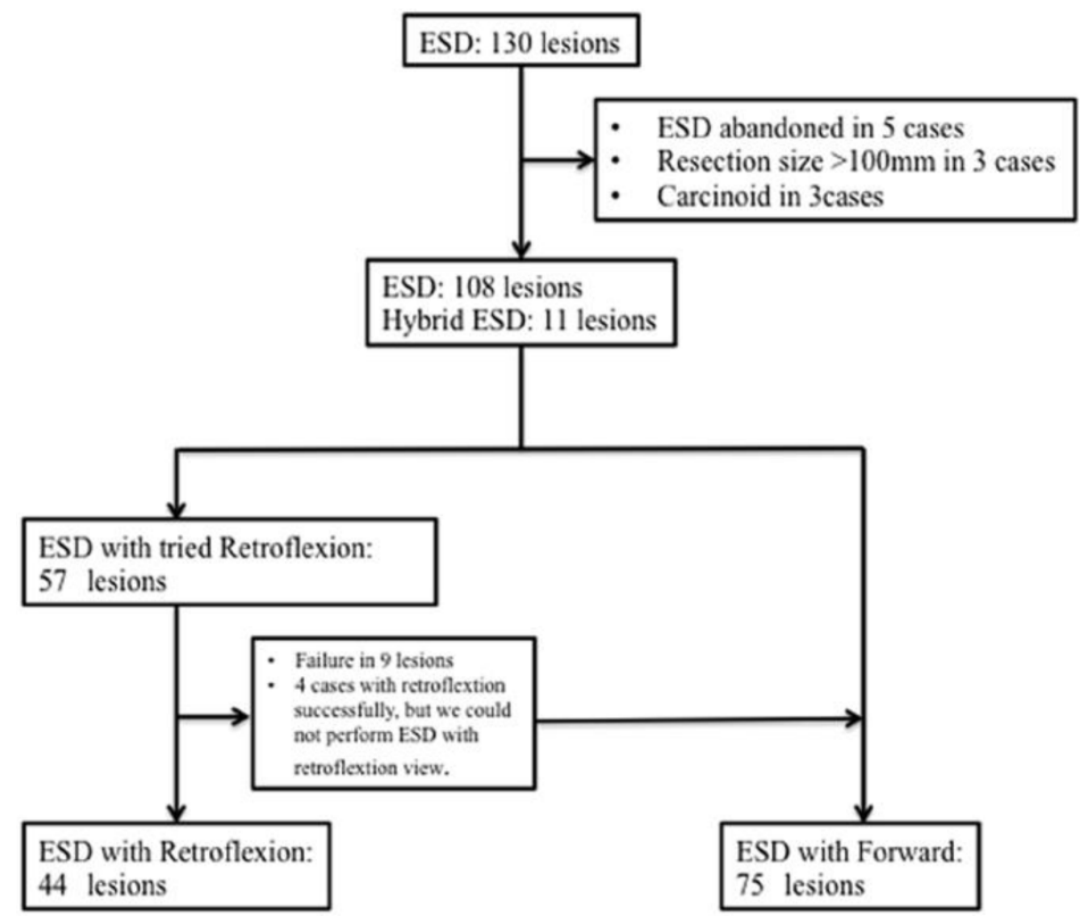

Figure 1. Flowchart showing patient inclusion and clinical courses. ESD, endoscopic submucosal dissection. 


\section{Clinicopathological characteristics and histological assessments}

The tumor types were classified according to the Paris classification (19) and Kudo's classification (20) as type $0-\mathrm{I}$ (protruded) and 2 LST subtypes. The LST subtypes were also characterized as LST-G or LST-NG. The extent of the tumor was determined by differences in the color, height, morphological features, and pit patterns between the neoplastic and non-neoplastic mucosa. The tumor depth was assessed using morphological features. Tumors that showed evidence of regions of hardness, irregular nodules, ulceration, or submucosal tumor-like marginal elevation were suspected to be massive SM tumors $>1,000 \mu \mathrm{m}$ (SM2 or deeper).

Histological classification was performed according to the Vienna classification of gastrointestinal epithelial neoplasia (21-22). The extension of tumor cells to the resected margin was classified as follows: complete resection (R0), in which the lateral and basal resection margins were tumor-free (and en bloc resection was essential); incomplete resection (R1), in which the tumor extended into the lateral or basal margins or was not evaluable (Rx); or margins that could not be evaluated. Curative resection was achieved when both the lateral and vertical margins of the specimen/specimens were cancer-free and there was no submucosal invasion $\geq 1000 \mathrm{~mm}$ (SM1), lymphatic invasion, vascular involvement, or poorly differentiated components (23).

\section{Preparation prior to colorectal ESD}

The patients were given a low-fiber diet the day before ESD and were prescribed $24 \mathrm{mg}$ of sennoside (Pursennid; Novartis Pharma, Tokyo, Japan) the night before ESD. Patients underwent bowel preparation with either $1.8 \mathrm{~L}$ of magnesium citrate or $2 \mathrm{~L}$ of polyethylene glycol in the morning of the day of ESD. Immediately prior to the procedure, an intravenous injection containing $20 \mathrm{mg}$ of scopolamine butyl bromide (Buscopan; Nippon Boehringer Ingelheim, Tokyo, Japan) or $1 \mathrm{mg}$ of glucagon (Glucagon G Novo; Eisai, Tokyo, Japan), $15 \mathrm{mg}$ of pentazocine (Pentazin; Sankyo Pharmaceuticals, Tokyo, Japan), and $2.5 \mathrm{mg}$ of midazolam (Dormicum; Astellas Pharma, Tokyo, Japan) was administered. During the procedure, 1.25 $\mathrm{mg}$ of midazolam was administered as necessary.

\section{ESD technique}

All procedures were performed using a standard colonoscope (EVIS PCF-Q260AI or GIF H260Z, Olympus Medical Systems Co., Tokyo, Japan) and carbon dioxide. The disposable distal attachment
(D-201-13404; Olympus Medical Systems Co., Tokyo, Japan) was mounted onto the tip of the endoscope. A VIO 300D (ERBE Elektromedizin, Tübingen, Germany) or ICC200 (Erbe Elektromedizin Ltd., Tubingen, Germany) generator was used as the power source for the electrical cutting and coagulation. During the colorectal ESD procedure, a dual knife (Olympus Medical Systems Co., Tokyo, Japan) and insulated tipped (IT) knife (Olympus Medical Systems Co., Tokyo, Japan) were used. However, if the scope was positioned against the lesion or a rich vascular area, the dual knife was exchanged for a scissor-type grasping knife (Clutch cutter). A mixture of $1 \%$ hyaluronic acid (Mucoup; Johnson \& Johnson K.K., Tokyo, Japan) and 10\% glycerin (Glycerol; Chugai Pharmaceutical Co., Tokyo, Japan) was used as the injection liquid.

\section{Retroflexion technique}

Retroflexion was attempted in cases in which forward viewing did not allow access to a proximal side of the lesion or in which access was considered extremely difficult. In these cases, retroflexion also enabled a more en face approach. The lesions were considered appropriate for retroflexion based on their size and accessibility.

A successful retroflexion was defined as the ability to visualize the proximal side of the tumor lesion. If the lesion was located on the proximal sides of folds or flexures and was invisible on the proximal side, we attempted to use retroflexion and performed a submucosal injection (Figure 2). After retroflexion was achieved, we precut and dissected the proximal side of the tumor. After the proximal side of the lesion was sufficiently dissected, we performed submucosal dissection in the forward view (Figure 3). However, the retroflexion technique could not be performed in cases of colorectal deformity and stenosis. In these situations, we performed colorectal ESD exclusively in the forward view (Figure 4). We did not routinely attempt to achieve retroflexion in the bottom of the cecum or the distal ileocecal valve.

\section{Treatment protocol}

The patients were admitted to our unit on the day before ESD. After the colorectal ESD procedure, the patients underwent a 2-day fasting period. They were discharged from the hospital 7 days after undergoing colorectal ESD. We analyzed the laboratory data on postoperative days 1 and 4 . All patients were prescribed cefmetazole (Daiichi-Sankyo Co., Tokyo, Japan) for 3 days after colorectal ESD. Upon discharge, the patients were followed up for 30 days (i.e., outpatient visits) to record late adverse events. 


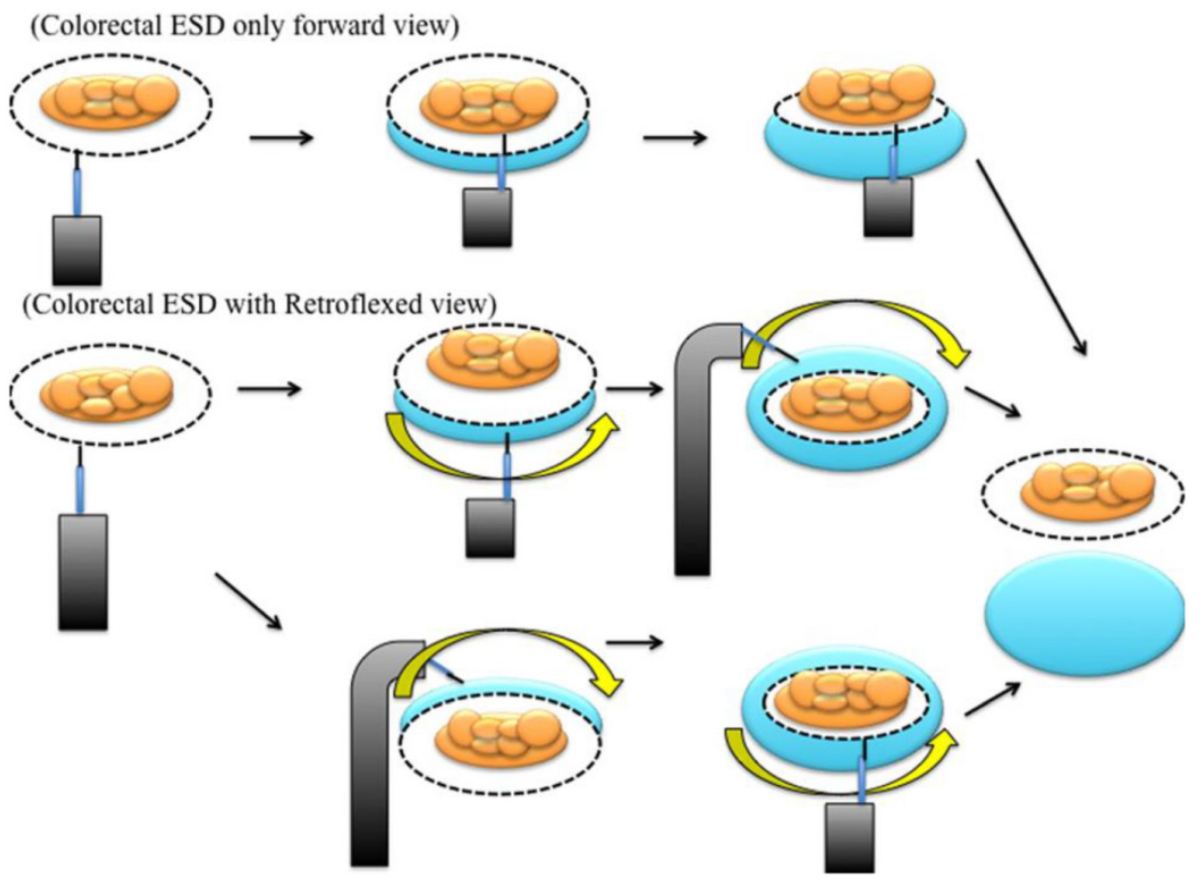

Figure 2. Diagram of an endoscopic mucosal dissection with forward and retroflexed views.
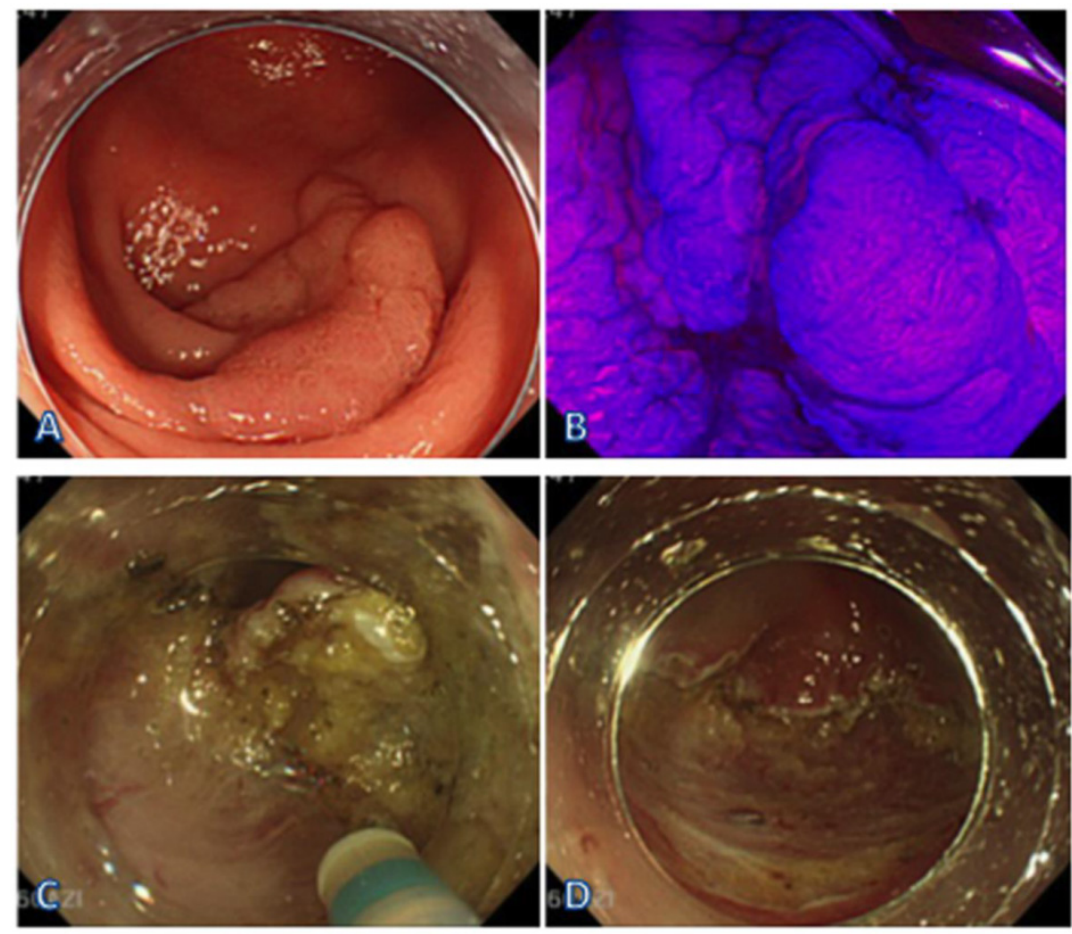

Figure 3. ESD obtained with a forward view. (A) LST-G in the cecum. (B) Endoscopic view of the lesion sprayed with crystal violet. (C) ESD obtained with a forward view at the cecum. (D) The view after the resection. 


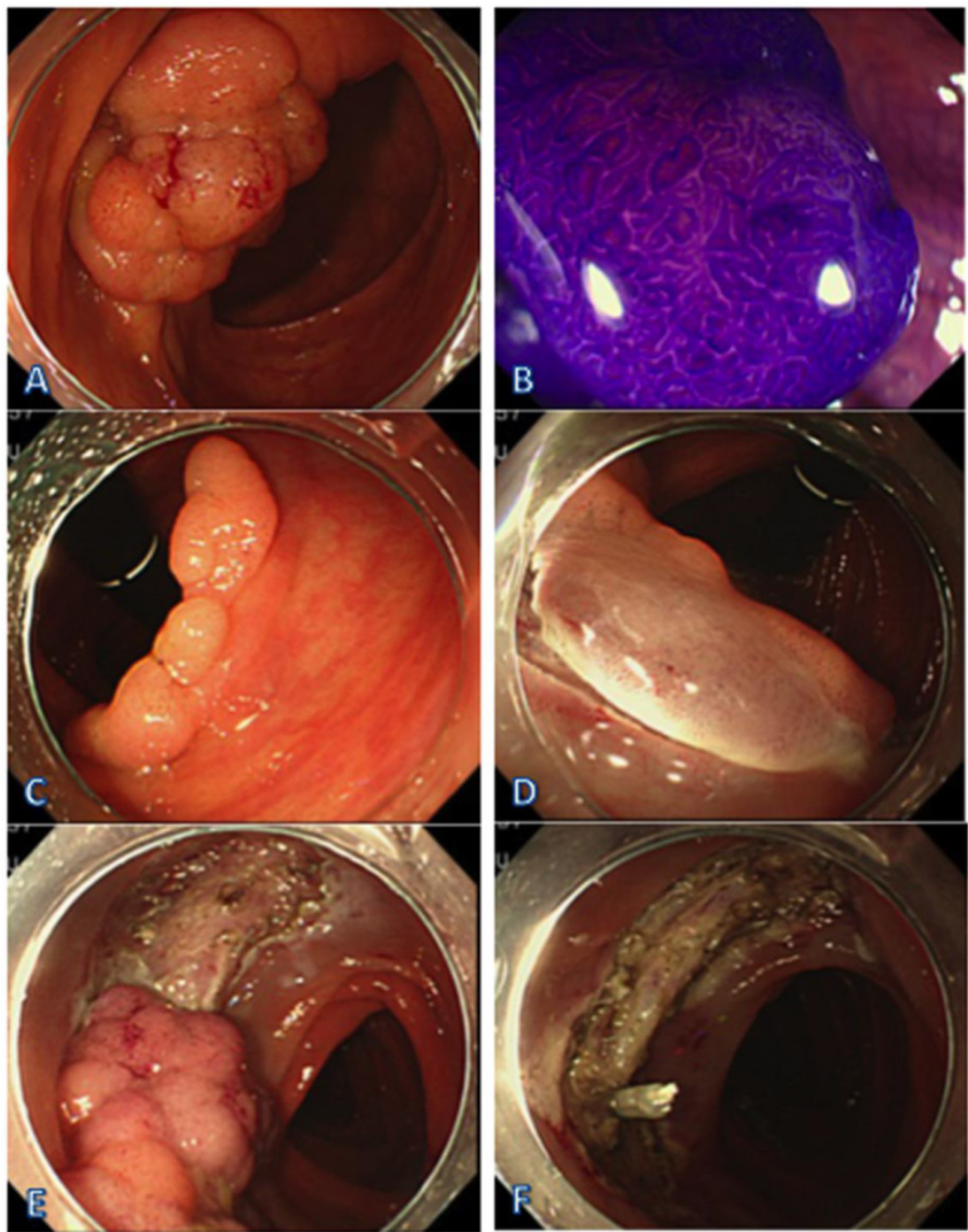

Figure 4. ESD with a retroflexed view. (A) LST-G in the ascending colon. (B) Endoscopic view of the lesion sprayed with crystal violet. (C) Retroflexed view at the ascending colon. (D) Precut with a retroflexed view at the ascending colon. (E) ESD conducted with a forward view. (F) The view after the resection.

\section{Measured outcomes}

The total procedure times, retroflexion-related complications, and success rates were assessed by recorded video after the procedures and were evaluated as primary end points. The procedure time was defined as the time from the circumferential marking around the lesions to the complete removal of the tumor.

Adverse events, delayed bleeding, and perforation after colorectal ESD were evaluated as secondary end points. Delayed bleeding was defined as clinical evidence of bleeding manifested by melena or hematochezia from 0 to 14 days after the procedure that required endoscopic hemostasis. Immediate perforation during an ESD procedure was defined as perforation occurring during the procedure, and delayed perforation was defined as perforation occurring after completion of the ESD procedure.

\section{Statistical analysis}

The absolute and relative frequencies of qualitative variables were calculated for each group. The continuous variables were expressed as the mean \pm standard deviation (SD). The continuous variables were compared using Student's t-test if the data were normally distributed or the Wilcoxon test if the data were not normally distributed. Pearson's chi-square test or Fisher's exact test was used to analyze the categorical data to compare proportions. All $p$-values were two-tailed, and $p<0.05$ was defined as statistically significant. Data analysis was conducted using JMP version 9.0 (SAS Institute, Cary, NC, USA).

\section{Results}

Between April 2009 and April 2013, we performed colorectal ESD in 130 patients with superficial colorectal neoplasms. The patient characteristics and tumor clinicopathological features are summarized in 
Table 1. A total of 119 patients (77 males and 42 females) with a mean tumor size of $27.2 \mathrm{~mm}$ were enrolled in the study. The patients were assigned to undergo colorectal ESD with or without a retroflexed view.

The patient characteristics and tumor clinicopathological features are summarized in Table 1 . There was no significant difference in gender, age, or tumor location between the groups. However, tumor size and resection size did differ between the groups, with the retroflexed group presenting significantly larger tumors. The mean tumor size was $32.2 \mathrm{~mm}$ in the retroflexed view group and $24.2 \mathrm{~mm}$ in the forward view group $(p=0.0019)$. The resection size was significantly larger in the retroflexed group because the tumors were larger.

Table 1. Patient characteristics and clinicopathological features

\begin{tabular}{|c|c|c|c|}
\hline & Retroflexed group & Forward group & $\mathrm{p}$ value \\
\hline & $(n=44)$ & $(n=75)$ & \\
\hline Gender, male/female & $32 / 12$ & $45 / 30$ & 0.1608 \\
\hline Age, years, mean $\pm S D$ & $70.5 \pm 10$ & $68.7 \pm 9.5$ & 0.3549 \\
\hline Tumor size, mm, mean \pm SD & $32.2 \pm 15.3$ & $24.2 \pm 12.0$ & 0.0019 \\
\hline Resection size, $\mathrm{mm}$, mean $\pm \mathrm{SD}$ & $39.4 \pm 14.3$ & $30.1 \pm 13.4$ & 0.0006 \\
\hline Location & & & 0.4676 \\
\hline Cecum & 7 & 12 & \\
\hline Ascending colon & 10 & 11 & \\
\hline Transverse colon & 2 & 6 & \\
\hline Descending colon & 0 & 6 & \\
\hline Sigmoid colon & 10 & 13 & \\
\hline Rectum & 15 & 27 & \\
\hline Macroscopic type (\%) & & & 0.7497 \\
\hline LST-G & $27(62)$ & $44(59)$ & \\
\hline LST-NG & $8((18)$ & $15(20)$ & \\
\hline Depressed & $0(0)$ & $1(1)$ & \\
\hline Protruded & $6(14)$ & $11(15)$ & \\
\hline Recurrent & $3(6)$ & $4(5)$ & \\
\hline Pathological findings (\%) & & & 0.2851 \\
\hline Adenoma & 14 & 38 & \\
\hline Mucosal cancer & 21 & 28 & \\
\hline SM-slight cancer & 5 & 3 & \\
\hline SM-deep cancer & 4 & 6 & \\
\hline Vessel infiltration & $3(7)$ & $5(7)$ & 0.9746 \\
\hline Ulcer presentation & $1(2)$ & $3(4)$ & 0.6138 \\
\hline
\end{tabular}

The retroflexion technique was successful in $84.2 \%$ of patients. The success ratios of retroflexion in the right-sided colon and rectum were higher than those of retroflexion in the left-sided colon and sigmoid colon. The resected tumor diameter tended to be larger in the retroflexed group than in the forward group, but there were no significant differences. There were no perforations in any of the patients and no complications related to retroflexion techniques.

Table 2 summarizes the clinical outcomes in both groups. En bloc resection was achieved for 44 of the 44 lesions $(100 \%)$ in the retroflexed group and 72 of the 75 lesions $(96.0 \%)$ in the forward view group. The mean procedure time was $103.6 \pm 55.8 \mathrm{~min}$ in the retroflexed group, as compared with $108.0 \pm 66.5 \mathrm{~min}$ in the forward view group. The mean procedure time for tumors $>40 \mathrm{~mm}$ was significantly shorter in the retroflexed view group relative to the forward view group. Additionally, the mean dissection speed per unit area was $10.53 \pm 7.67 \mathrm{~mm}^{2} / \mathrm{min}$, and significantly faster in the retroflexed group, as compared with $5.95 \pm 4.44$ $\mathrm{mm}^{2} / \mathrm{min}$ in the forward group.

The complication data are summarized in Table 3. Immediate bowel perforations occurred in two patients $(2.7 \%)$ in the forward group, and there was delayed bleeding in two patients $(4.3 \%)$ in the retroflexed view group. However, there were no significant between-group differences in complications and hospital admissions.

Table 2. En bloc and complete resection rates and procedure times according to tumor size

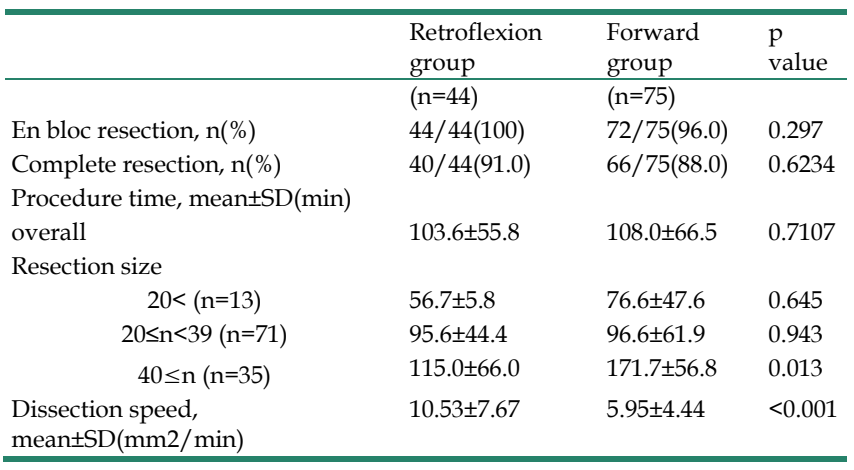

Table 3. Complications related to the procedure

\begin{tabular}{llll}
\hline & $\begin{array}{l}\text { Retroflexed } \\
\text { group }\end{array}$ & $\begin{array}{l}\text { Forward } \\
\text { group }\end{array}$ & $\begin{array}{l}\mathrm{p} \\
\text { value }\end{array}$ \\
\hline & $(\mathrm{n}=44)$ & $(\mathrm{n}=75)$ & \\
Immediate perforation, $\mathrm{n}(\%)$ & $0 / 44(0)$ & $2 / 75(2.7)$ & 0.2861 \\
Delayed perforation, $\mathrm{n}(\%)$ & $0 / 44(0)$ & $0 / 75(0)$ & \\
$\begin{array}{l}\text { Delayed bleeding, } \mathrm{n}(\%) \\
\text { Hospital admission, }\end{array}$ & $2 / 44(4.3)$ & $0 / 75(0)$ & 0.0626 \\
mean $\pm \mathrm{SD}$ (day) & $8.2 \pm 0.9$ & $8.6 \pm 2.2$ & 0.156 \\
\hline
\end{tabular}

\section{Discussion}

The retroflexion technique is commonly used during colonoscopy to improve the detection of neoplasia in the distal rectum $(8,24-27)$; polypectomy performed with retroflexion is a useful method for removing colon polyps that are difficult to access (5). The value of using retroflexion techniques proximal to the rectum is that this approach enables polypectomy of difficult-to-access lesions located on the proximal sides of folds and flexures (5-6).

In the present study, we made two important clinical observations. First, the retroflexed view could 
be used to remove lesions $>40 \mathrm{~mm}$ and resulted in shorted procedure times and an increased en bloc resection rate. Second, the success ratio of retroflexion was $84.2 \%$, with values for the right-sided colon and rectum higher than those for the left-sided colon and sigmoid colon, and there were no complications related to the use of retroflexed views.

Retroflexion was able to shorten the procedure time because it reduced the respiratory variation in visual fields and stabilized the scope. In particular, in cases in which the LST and protruded polyp were large in size, we could not detect the proximal side of the lesions, and it was therefore difficult to perform the ESD procedure on the proximal side of the lesions. Additionally, when the retroflexion technique was successful, it contributed to patient safety and scope stability because the scope was fixed in the colorectal lumen and there was a reduction in respiratory variation, especially on the right side of the colon. A steady cut with fixing of the knife to the target decreased a potential risk of major complications, such as perforation and bleeding, because of an unexpected incision caused by the heart beat or respiratory movement.

Difficulty regarding the use of ESD is associated with both the location and size of the lesion (28-30), because procedure times increase as the tumor location extends into the colon and the tumor size increases (30). The risk factors for perforation and delayed bleeding during gastric ESD include the tumor location, old age, presence of fibrosis, and long procedure times (28-29). Therefore, shortening the length of the procedure may reduce complications.

There are many electrical devices that can reduce the difficulties associated with colorectal ESD procedures (31). The flush knife (DK2618JN; Fujifilm, Tokyo, Japan) is a needle knife that has the added advantage of allowing local injection (37). The newly developed insulation-tipped electrosurgical knife (IT Knife Nano, KD-612Q: Olympus Optical Co., Tokyo, Japan) has a smaller insulation tip than the previous version and the short blade design results in safer procedures by reducing the risk of perforation (38). Grasping scissor-type forceps do not require adept technical skills because they can facilitate manipulations such as rotation, grasping, incision, and resection $(39,40)$.

In particular, ESD experts express the following common opinions: 1) sodium hyaluronate solution is valuable for ESD procedures (32-33); 2) attachments are generally used to achieve a clear visual field; and 3) a carbon dioxide insufflation system is essential for reducing abdominal distention (16,34). Additionally, position changes using the effect of gravity are sometimes effective in maintaining a good visual field (35).
If possible, retroflex manipulation is also effective for the resection of lesions on the oral side (36).

In our study, the success rate of retroflexion in the sigmoid colon was lower relative to that in other locations because it was difficult to transmit sufficient torque to the bending section to achieve retroflexion when a loop was present. The reasons for retroflexion failure included difficulty in transmitting sufficient torque because a loop was present ( $n=4$ cases) and the narrowness of the lumen ( $n=5$ cases). In the current study, we could not use the insertion tube to aid the retroflexion technique, and the ability to achieve retroflexion in the proximal colon was primarily related to whether or not there was substantial bending or looping of the insertion tube of the instrument (9). Thus, successful retroflexion may be achieved by using the insertion tube for pediatric colonoscopy.

In this study, there were no perforations or complications related to using the retroflexion technique. Although bowel perforation has been reported to result from retroflexion (36), there were no major procedure-related complications, such as perforation or significant bleeding that required transfusion, associated with the retroflexion technique.

This study had several limitations. First, it was retrospective and was affected by the limitations associated with its investigational design. Second, the sample size for the retroflexion group was relatively small. Third, because the strategy for colorectal ESD was determined by the endoscopists, selection bias could have affected the outcome.

\section{Conclusions}

In this study, the retroflexed view was used to remove lesions of $>40 \mathrm{~mm}$ in size. Moreover, the retroflexion approach shortened procedure times and may contribute to increased rates of en bloc resection.

\section{Abbreviations}

ESD: endoscopic submucosal dissection; EMR: endoscopic mucosal resection; LST: lateral spreading tumor.

\section{Acknowledgment}

We thank Dr. Makoto Oryu for providing technical and editorial assistance.

\section{Conflicts of interest}

The author(s) declare no conflicts of interest.

\section{References}

1. Saito Y, Uraoka T, Yamaguchi Y, Hotta K, Sakamoto N, Ikematsu H, et al. A prospective, multicenter study of 1111 colorectal endoscopic submucosal dissections (with video). Gastrointest Endosc. 2010; 72: 1217-25.

2. Terasaki M, Tanaka S, Oka S, Nakadoi K, Takata S, Kanao H, et al. Clinical outcomes of endoscopic submucosal dissection and endoscopic mucosal re- 
section for laterally spreading tumors larger than $20 \mathrm{~mm}$. J Gastroenterol Hepatol. 2012; 27: 734-40.

3. Nakajima T, Saito Y, Tanaka S, Iishi H, Kudo SE, Ikematsu H, et al. Current status of endoscopic resection strategy for large, early colorectal neoplasia in Japan. Surg Endosc. 2013

4. Tanaka S, Oka S, Kaneko I, Hirata M, Mouri R, Kanao H, et al. Endoscopic submucosal dissection for colorectal neoplasia: possibility of standardization. Gastrointest Endosc. 2007; 66: 100-7.

5. Rex DK, Khashab M. Colonoscopic polypectomy in retroflexion. Gastrointest Endosc. 2006; 63: 144-8.

6. Pishvaian AC, Al-Kawas FH. Retroflexion in the colon: a useful and safe technique in the evaluation and resection of sessile polyps during colonoscopy. Am J Gastroenterol. 2006; 101: 1479-83.

7. Rex DK, Vemulapalli KC. Retroflexion in colonoscopy: why? Where? When? How? What value? Gastroenterology. 2013; 144: 882-3.

8. Saad A, Rex DK. Routine rectal retroflexion during colonoscopy has a low yield for neoplasia. World J Gastroenterol. 2008; 14: 6503-5.

9. Hewett DG, Rex DK. Miss rate of right-sided colon examination during colonoscopy defined by retroflexion: an observational study. Gastrointest Endosc. 2011; 74: 246-52.

10. Akahoshi K, Honda K, Motomura Y, Kubokawa M, Okamoto R, Osoegawa T, et al. Endoscopic submucosal dissection using a grasping-type scissors forceps for early gastric cancers and adenomas. Dig Endosc. 2011; 23: 24-9.

11. Oka S, Tanaka S, Takata S, Kanao H, Chayama K. Usefulness and safety of SB knife Jr in endoscopic submucosal dissection for colorectal tumors. Dig Endosc. 2012; 24 Suppl 1: 90-5.

12. Kudo S, Kashida H, Tamura T, Kogure E, Imai Y, Yamano H, et al. Colonoscopic diagnosis and management of nonpolypoid early colorectal cancer. World J Surg. 2000; 24: 1081-90.

13. Saito Y, Fujii T, Kondo H, Mukai H, Yokota T, Kozu T, et al. Endoscopic treatment for laterally spreading tumors in the colon. Endoscopy. 2001; 33: $682-6$.

14. Tanaka S, Haruma K, Oka S, Takahashi R, Kunihiro M, Kitadai Y, et al. Clinicopathologic features and endoscopic treatment of superficially spreading colorectal neoplasms larger than $20 \mathrm{~mm}$. Gastrointest Endosc. 2001; 54: 62-6.

15. Uraoka T, Saito Y, Matsuda T, Ikehara H, Gotoda T, Saito D, et al. Endoscopic indications for endoscopic mucosal resection of laterally spreading tumours in the colorectum. Gut. 2006; 55: 1592-7.

16. Saito Y, Uraoka T, Matsuda T, Emura F, Ikehara H, Mashimo Y, et al. A pilot study to assess the safety and efficacy of carbon dioxide insufflation during colorectal endoscopic submucosal dissection with the patient under conscious sedation. Gastrointest Endosc. 2007; 65: 537-42.

17. Ishiguro A, Uno Y, Ishiguro Y, Munakata A, Morita T. Correlation of lifting versus non-lifting and microscopic depth of invasion in early colorectal cancer. Gastrointest Endosc. 1999; 50: 329-33.

18. Kobayashi N, Saito Y, Sano Y, Uragami N, Michita T, Nasu J, et al. Determining the treatment strategy for colorectal neoplastic lesions: endoscopic assessment or the non-lifting sign for diagnosing invasion depth? Endoscopy. 2007; 39: 701-5.

19. The Paris endoscopic classification of superficial neoplastic lesions: esophagus, stomach, and colon: November 30 to December 1, 2002. Gastrointest Endosc. 2003: 58: S3-43.

20. Kudo S, Kashida H, Tamura T, Kogure E, Imai Y, Yamano H, et al. Colonoscopic diagnosis and management of nonpolypoid early colorectal cancer. World J Surg. 2000; 24: 1081-90.

21. Schlemper RJ, Riddell RH, Kato Y, Borchard F, Cooper HS, Dawsey SM, et al. The Vienna classification of gastrointestinal epithelial neoplasia. Gut. 2000; 47: 251-5.

22. Dixon MF. Gastrointestinal epithelial neoplasia: Vienna revisited. Gut. 2002; 51: 130-1.

23. Kitajima K, Fujimori T, Fujii S, Takeda J, Ohkura Y, Kawamata H, et al. Correlations between lymph node metastasis and depth of submucosal invasion in submucosal invasive colorectal carcinoma: a Japanese collaborative study. J Gastroenterol. 2004; 39: 534-43.

24. Cutler AF, Pop A. Fifteen years later: colonoscopic retroflexion revisited. Am J Gastroenterol. 1999; 94: 1537-8.

25. Grobe JL, Kozarek RA, Sanowski RA. Colonoscopic retroflexion in the evaluation of rectal disease. Am J Gastroenterol. 1982; 77: 856-8

26. Hanson JM, Atkin WS, Cunliffe WJ, Browell DA, Griffith CD, Varma JS, et al. Rectal retroflexion: an essential part of lower gastrointestinal endoscopic examination. Dis Colon Rectum. 2001; 44: 1706-8.

27. Varadarajulu S, Ramsey WH. Utility of retroflexion in lower gastrointestinal endoscopy. J Clin Gastroenterol. 2001; 32: 235-7.

28. Okada K, Yamamoto Y, Kasuga A, Omae M, Kubota M, Hirasawa T, et al. Risk factors for delayed bleeding after endoscopic submucosal dissection for gastric neoplasm. Surg Endosc. 2011; 25: 98-107.

29. Toyokawa $\mathrm{T}$, Inaba $\mathrm{T}$, Omote S, Okamoto A, Miyasaka R, Watanabe $\mathrm{K}$, et al. Risk factors for perforation and delayed bleeding associated with endoscopic submucosal dissection for early gastric neoplasms: analysis of 1123 lesions. J Gastroenterol Hepatol. 2012; 27: 907-12.

30. Ahn JY, Choi KD, Choi JY, Kim MY, Lee JH, Choi KS, et al. Procedure time of endoscopic submucosal dissection according to the size and location of early gastric cancers: analysis of 916 dissections performed by 4 experts. Gastrointest Endosc. 2011; 73: 911-6
31. Tanaka S, Oka S, Chayama K. Colorectal endoscopic submucosal dissection: present status and future perspective, including its differentiation from endoscopic mucosal resection. J Gastroenterol. 2008; 43: 641-51.

32. Fujishiro M, Yahagi N, Nakamura M, Kakushima N, Kodashima S, Ono S, et al. Successful outcomes of a novel endoscopic treatment for GI tumors: endoscopic submucosal dissection with a mixture of high-molecular-weight hyaluronic acid, glycerin, and sugar. Gastrointest Endosc. 2006; 63: 243-9.

33. Yamamoto H, Kawata H, Sunada K, Sasaki A, Nakazawa K, Miyata T, et al. Successful en-bloc resection of large superficial tumors in the stomach and colon using sodium hyaluronate and small-caliber-tip transparent hood. Endoscopy. 2003; 35: 690-4.

34. Kikuchi T, Fu KI, Saito Y, Uraoka T, Fukuzawa M, Fukunaga S, et al. Transcutaneous monitoring of partial pressure of carbon dioxide during endoscopic submucosal dissection of early colorectal neoplasia with carbon dioxide insufflation: a prospective study. Surg Endosc. 2010; 24: 2231-5.

35. Hotta K, Yamaguchi Y, Saito Y, Takao T, Ono H. Current opinions for endoscopic submucosal dissection for colorectal tumors from our experiences: indications, technical aspects and complications. Dig Endosc. 2012; 24 Suppl 1: 110-6

36. Ahlawat SK, Charabaty A, Benjamin S. Rectal perforation caused by retroflexion maneuver during colonoscopy: closure with endoscopic clips. Gastrointest Endosc. 2008; 67: 771-3.

37. Toyonaga T, Man-i M, Chinzei R et al. Endoscopic treatment for early stage colorectal tumors: The comparison between EMR with small incision, simplified ESD, and ESD using the standard flush knife and the ball tipped flush knife. Acta Chir Iugosl. 2010; 57: 41-46.

38. Hotta K, Yamaguchi Y, Saito Y et al. Current opinions for endoscopic submucosal dissection for colorectal tumors from our experiences: Indications, technical aspects and complications. Dig. Endosc. 2012; 24 (Suppl 1): 110-116.

39. Honma K, Kobayashi M, Watanabe $\mathrm{H}$ et al. Endoscopic submucosal dissection for colorectal neoplasia. Dig Endosc. 2010; 22: 307-311.

40. Akahoshi K, Honda K, Akahane $\mathrm{H}$ et al. Endoscopic submucosal dissection by using a grasping-type scissors forceps: a preliminary clinical study (with vide). Gastroint Endosc 2008; 67: 1128-1133. 